to little modification. From the first the patient's exercise took the form of useful work. For more than a year tuberculin was given systematically to a certain group of the patients, but we were not favourably impressed by it.

There has been a farm colony on a small scale in Norfolk for the last eighteen months, and the experience gained there has been most instructive. Generally speaking, the way in which the men's healths have been maintained, or more commonly improved, while they followed some useful occupation, has been highly encouraging. Some of the colonists came to us with the sputum already free from tubercle bacilli, and with signs of only past mischief. With only one or two exceptions these men have gone steadily forwards, and under the conditions of healthy housing, of good feeding, and of regulated work have required little attention. But the men with bacilli still present, and with physical signs placing them perhaps in Class II, have had to be watched more carefully. Even of them the majority have done surprisingly well. At the same time a week seldom passes without one of the colonists being pulled up with the threat of a smaller or greater set-back. Apart from elevation of temperature from increased frequency of pulse or from loss of weight, the jealous eye of the nurse notices loss of appetite or some other indication of lowered health. When this man is examined it may often be found that, sure enough, an extension of his disease has occurred.

Tuberculosis in all its phases is characterized by a broken course with ups and downs, and success in its management depends on any tendency to relapse being immediately detected and properly dealt with. This essential require. ment in the after.care of the ex-sanatorium patient seems to us to be best met by the colony scheme. For the man whose tuberculosis has become arrested it is not of supreme importance whether his employment be out of doors or indoors. Of course it is an advantage if he can spend twenty-four hours each day in the fresh air, but it is of more importance to provide that the number of hours and the arduousness of the work be strictly regulated according to the man's ascertained capability.

Some years ago we got out figures for the purpose of comparing the after-results in our ex-sanatorium patients, according to their resumption of an indoor occupation, to their resumption of an outdoor occupation, or to their changing from indoor to outdoor work. Our statistics showed, however, no striking differences among the three groups. We know that there are many factors to be taken into consideration, such as the healthiness or the reverse of the workroom, the home conditions, the amount of the earnings, and the consequent sufficiency or scarcity of good food, and chiefly whether or not the individuals are worked beyond their strength. Our agricultural labourers, for instance, have not yielded good after-results. Their working hour's are spent in the open air, but we know that their toil is arduous, that they are often badly housed, and have been badly fed. On the other hand, the few master farmers who have passed through the sanatorium have mostly continued to do well. Presumably they were able to choose their kind and amount of work, and, of course, they were able to live well.

While indoor work as such is not necessarily harmful, so long as it is not too strenuous, there is information in regard to certain industries which marks them as unfavourable for the ex-sanatorium patient. In Norwich, for example, the clerk of the City Insurance Committee finds that, of 439 men applying for sanatorium benefit, 33.5 per cent. were working. in boot factories, and that of 297 women 20.2 per cent. were thus employed. Our sanatorium patients who were forced by circumstances to return to the boot factories have done no better than we should have expected. They are unfitted to take their places beside able-bodied men and to work full time at top speed and perhaps under unhealthy conditions. The experience at Papworth and elsewhere shows, however that the consumptive man can do remunerative work in the model factory, so long as his exertions are adjusted to his physical powers.

Dr. F. Stanley Tinker suggests the institution of municipal workshops, the men going backwards and forwards from their homes, and working under medical supervision. There may be other solutions of the problem, but we are convinced that for the first five years at least the patient with pulmonary tuberculosis should be kept under close and expert super vision. Such work should be allowed as is found to be compatible with the retention of his ascendancy over the disease. He must be relieved of anxiety about the maintenance of himself and his dependants, his housing must be seen to, and there must be no difficulty in securing for him return to the sanatorium from time to time if his malady reasserts itself. The difficulty of such provision is, of course, the financial one, but unless this difficulty is overcome part of the expenditure on sanatoriums is thrown away. We know that it is possible not only to prolong the lives of these men, but to make them useful members of the community.

\section{HAEMORRHAGIC COLITIS.}

BY

J. IV. GEARY GRANT, F.R.C.S.ENG.,

SENIOR ASBISTANT SURGFON, RING RDWARD VII HOSPITAL, AND CHIEP ASSISTANT IN THE BORGICAL UNIT, WELSH NATIONAL

The following two cases, which, in view of the fact that haemorrhage and the resulting severe anaemia were the leading symptoms, I have ventured to term "haemorrhagic colitis," were in the King Edward VII Hospital about the same time under the care of Dr. Mitchell Stevens, to whose courtesy and to that of Mr. Cornelius Griffiths, who operated on the first case, I am indebted for permission to give this account.

\section{Case r.}

The patient, a housemaid aged 37, stated that for fourteen days she had passed a quantity of blood and mucus in the motions, which averaged five a day. She had had an attack of "dysentery", at Regina, Canada, in 1917, and two similar attacks subsequently. When examined on October 26th, 1920, the temperature was normal. The faeces contained blood, mucus, and pus cells, and $B$. coli. An autogenous vaccine was prepared and administered At Dr. Mitchell Stevens's request I examined her with the sigmoidoscope, but was unable to get the instrument past the pelvic brim. This was largely oring to the continual flow of blood which obscured the view. The pelvic colon had a granular appearance, and in the upper part there were numerous papillary elevations, the mucous membrane bleeding at the slightest touch. No definite ulcers were seen, but the appearance at the upper part of the pelvic colon suggested carcinoma to me

On November 28th, 1920, Mr. Cornelius Griffiths opened the abdomen by a median subumbilical incision and drew out the iliac colon which was found to be thickened. A portion of the wall was removed for examination and reported to be haemangiomatous. There was not, however, any localized growth but a diffuse thickening of the mucous membrane. A faecal fistula was established. For a month the temperature was irregular, averaging $100^{\circ}$ to $101^{\circ}$. Blood and pus passed from the colostomy opening and from the anus, and staphylococci were found in the urine. The Wassermann reaction was negative.

On January 14th, 1921, Mr. Griffiths closed the fistula, and in May she was discharged to a convalescent home, all symptoms having cleared up.

CAse II.

This patient, a clerk aged 21, was admitted under the care of Dr. Mitchell Stevens on January 17th, 1921 . He stated that for month before admission he had passed large quantities of blood from the anus, and that he had passed blood also in small quantities for eighteen months previously; he suffered no pain. He had had no previous illnesses, lived in a mining district, and had not been abroad. The rectum was washed out, and the returned fluid contained blood, pus and. mucus. On January 20th, at Dr. Mitchell Stevens's request, I passed a sigmoidoscope, but I could not get it past the angulation at the pelvic brim. "The appearance was almost exactly the same as in the previous case. There was a continual flow of blood from the granular and friable mucous continual flow of blood from the granular and friable mucous
membrane of the pelvic colon. He was extremely anaemic and membrane of the pelvic colon. He was extremely. anaemic and
emaciated, and Dr. Mitchell Stevens felt that immediate surgical intervention was needed; the opinion we formed was that he probably had a polypus or imultiple adenomata in the colon.

On January 26 th, 1921, I opened the abdomen by a median subumbilical incision and drew out the iliac colon. Its wall was thickened and firm; the para-colic lymph glands were enlarged and two were removed for examination. A portion of the wall of the colon was also removed, and the report on this was wat it showed a haemangiomatous condition of the mucous membrane, showed a haemangiomatous condition of the mucous membrane, a. sigmoidoscope as far as the splenic flexure. The mucous mem brane simply presented a granular appearance and intense engorge ment and bled at a touch. There was no ulceration. As his condition was very bad, I fixed the loop of iliac colon in the wound and established a colostomy with a good spur. He was very collapsed after the operation, but with rectal saline and glucose he came round, but for two days vomited a good deal. The he came round, but for two days vomited a good deal. The
colostomy discharged pus and mucus freely, with small amounts colostomy discharged pus and mucus freely, with small amounts
of blood. It was washed out with saline and with collargol, and horse serum and calcium lactáte were administeréd.

A blood examination on February 2nd showed haemoglobin 65 per cent.; red blood cells, $3,640,000$; white cells, 16,000 ; the differential count gave polymorphs 76 per cent. small lymphocytes 10 per cent., large lymphocy tes 6 per cent., eosinophils 3 per cent., myelocytes 5 per cent. 
On March 16th a blood examination gave the following: Haemoglobin, 55 per cent.; red blood cells, 3,280,000; white cells, 8,000 : polymorphs 54 per cent., small lymphocytes 44 per cent., large lymphocytes 2 per cent.

The first count showed a high-grade secondary anaeria with a moderate leucocytosis; probably a post-haemorrhagic one; the second, with a higher anaemia, appeared to show a relative Tymphocytosis.

Washings from the rectum rielded a thick deposit of pus epithelial and connective tissue cells were obtained, and a few Entamoeba coli.

From a swab of the rectal mucus $B$. pyocyaneus was obtained in almost pure culture, and a vaccine of this was administered. Although Entamoeba coli is now generally held to be innocuous, yet, as some authorities hold that all intestinal amoebse are potentially pathological, he was placed on Fowler's solution by

The amounts of blood passed were quite small, but as the anaemia was increasing and he appeared to be steadily goin downhill, with Dr. Mitchell Stevens's permission I decided to perform appendicostomy with a view to securing a thorough flushing of the whole colon and this I did on March a thorath condition appeared so bad that my house-surgeon did not expect condition appeared so bad that

He was washed out from the appendicostomr opening dail $r$ with saline, and from then on steadily improved; indeed, the change from the condition of extreme pallor and emaciation was remark able. In a few weeks his face had filled ont and his colour had improved, and he expressed himself as feeling well. There were three factors that may bave contributed to the result-the administration of arsenic (which may have got rid of the amoebae), the pyocyaneis vaccine, and the more thorough flushing of the colon by means of the appendicostom

On June 26th I attempted the closure of the colostomy by Coffey's method. Owing to the presence of much prolapse and a very considerable spur the operation was difficult. Every attempt was made to get a thorough invagination, several tiers of catgut being used to secure inversion of the bowel wall, and ample drainage was provided, but four days later faeces came through the drainage tube, which passed down to the peritoneum. This, I. think, was due to angulation and the presence of the spur, which prevented the onward passage of intestinal contents into the dista segment. At the present time some faecal matter is passed negment. At the present time some faecal matter is passed further operation may be required to close this. In other respects his condition is very satisfactory. A blood examination made July 20th gave: Haemoglobin 65 per cent., red blood corpuscles $4,500,000$, white blood corpuscles 8,000-polymorphs 60 per cent., small lymphocytes 37 per cent., large lymphocytes 1 per cent., eosinophils 1 per cent., and basophils 1 per cent. The only organisms found in the stools were $B$. coli; the entamoebae and organisms found in the stools
$B$. pyocyaneus had disappeared.

These two cases differed from tropical dysentery in that there was no ulceration, and neither the bacillus of Shiga or the Entamoeba histolytica could be found. There was a remaxkable absence of pain in each. The mucous membrane presented a uniform granular appearance, which in the second case was observed to extend from the rectum to the splenic flexure, and which probably involved the whole lower bowel. This case was much the more severe, and we did not expect him to recover. I attribute a large share in the result to the appendicostomy, and if $I$ had a similar case to treat whieh did not respond to medical methods I should perform appendicostomy, and place a large flatus tube in the rectum, avoiding opening of the bowel, which in each case was done for diagnostic reasons, owing to the difficulty in investigating the colon higher up with the sigmoidoscope.

I may conclude with a few remarks on Coffey's method of closure of colostomies. I have tried this on four other occasions. In three, after some suppuration of the abdominal wound, a satisfactory closure ensued. In one a further operation was required. It is perhaps a safer operation than resection, but where there is considerable prolapse and extensive spur formation, it is difficult and unsatisfactory. The obstacle of the spur may be got over to some extent by the use of Balfour's rubber tube for a week or two before operation, but even then I think that the necessary invagination of the antimesenteric border is likely to cause distortion and angulation of the gut. In the second place, it does not seem to bein accord with the first principle of intestinal surgerynamedy, that secure union depends on the apposition of serous surfaces; as the operation is extraperitonoal this cannot be obtained. There is, however, probably less risk to life, and in suitable cases, with little prolapse, it isworth doing. China clay emulsion was also given during the later part of the treatment, but he was then recovering and its effect could not be judged.

Since the above was written, I am informed that the first patient suffered a relapse, but is now well again.

The second patient has also had a slight relapse, again passing a moderate smount of blood and mucus, and is at present bein treated at his home by injections of an autogenous coli vaccine I hope shortly to be able to close his colostomy

\section{NOTE ON THE INTRAPLEURAL PRESSURES IN ARTIFICIAL PNEUMOTHORAX.}

BY

JAMES LAWSON, B.Sc., M.D., M.R.C.P.E., assistant pHYSICIAN, TOR-Na-deE saNatoridu.

I sHodLd like to call attention to a feature which has not; as far as I am aware, already been noted and which deserves the consideration of those called upon to supervise the treatment of artificial pnoumothorax cases. I refer to the alteration which takes place in the intrapleural pressures with a change in the position of the patient.

This fact was first observed in the case of a patient in whom a right-sided artificial pneumothorax had been estab. lished. The patient always experienced a desire to cough when lying on the left side (the position in which all former refills had been carried out) and requested to be allowed to lie on his back. Puncture was made in the anterior axillary line in the fourth interspace and the manometer recorded pressures of $-2+5$, whereas the pressures reached at the previous refill fourteen days before were $-2+4$. Fluid was suspected, but the patient had been unconscious of splashing and physical examination had not suggested its presence. On rolling the patient into the left lateral position the pressures at once fell to $-4+2$.

Subsequent cases were investigated to ascertain the constancy of this variation, with the results shown in the table.

\begin{tabular}{|c|c|c|c|c|c|c|}
\hline \multirow{2}{*}{$\begin{array}{l}\text { Position of Artificial } \\
\text { Pneumothorax. }\end{array}$} & \multirow{2}{*}{ 讷: } & \multicolumn{2}{|c|}{$\begin{array}{c}\begin{array}{c}\text { Pressures } \\
\text { before Refll. }\end{array} \\
\text {. }\end{array}$} & \multirow{2}{*}{ 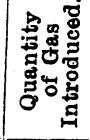 } & \multicolumn{2}{|c|}{$\begin{array}{l}\text { Pressures } \\
\text { after Refill. }\end{array}$} \\
\hline & & Lateral. & Dorsal. & & Lateral. & Dorsąl. \\
\hline $\begin{array}{l}\text { Case 1: Right-sided, com- } \\
\text { plete, with a small } \\
\text { quantity of fluid in } \\
\text { the pleura }\end{array}$ & 18 & $-2+4$ & $\begin{array}{l}+2+6 \\
+1+6\end{array}$ & $\begin{array}{l}\text { c.cm. } \\
100 \\
150\end{array}$ & $\begin{array}{l} \pm 0+5 \\
\pm 0+6\end{array}$ & $\begin{array}{l}+5+12 \\
+5+10\end{array}$ \\
\hline \multirow[t]{5}{*}{ Case 2: Left-sided } & 20 & $-4-2$ & $+2+5$ & 1,000 & $+3+5$ & $+8+12$ \\
\hline & 21 & $-3 \pm 0$ & $+2+7$ & 800 & $+3+5$ & $+10+12$ \\
\hline & 22 & $-1+1$ & $+8+12$ & 700 & $+6+8$ & $+12+14$ \\
\hline & 23 & $-2 \pm 0$ & $+3+6$ & 700 & $+4+8$ & $+11+13$ \\
\hline & 24 & $-5-2$ & $-2+5$ & 700 & $+3+5$ & $+4+10$ \\
\hline $\begin{array}{l}\text { Case 3: Right-sided, with } \\
\text { fluid } \\
\text { Case } 4: \text { Left-sided }\end{array}$ & $\begin{array}{r}36 \\
7\end{array}$ & $\begin{array}{l}-2+7 \\
-8-2\end{array}$ & $\begin{array}{l}+4+14 \\
-4+2\end{array}$ & $\begin{array}{l}100 \\
500\end{array}$ & $\begin{array}{c}+10+17 \\
\pm 0+4\end{array}$ & $\begin{array}{l}+14+22 \\
+2+7\end{array}$ \\
\hline \multirow[t]{4}{*}{ Case 5: Right-sided } & 18 & $-3+2$ & $\pm 0+4$ & 450 & $+6+10$ & $+8+12$ \\
\hline & 19 & $-3 \pm 0$ & $-1+2$ & 500 & $+3+8$ & $+6+11$ \\
\hline & 20 & $-4+2$ & $-2+4$ & 500 & $+6+10$ & $+9+13$ \\
\hline & 21 & $-4+2$ & $\pm 0+4$ & 425 & $+6+10$ & $+9+13$ \\
\hline \multirow[t]{5}{*}{ Case 6: Right-sided } & 12 & $-4+2$ & $-2+5$ & 350 & $-2+4$ & $+4+8$ \\
\hline & 13 & $-6 \pm 0$ & $-4+3$ & 450 & $-2+4$ & $+2+8$ \\
\hline & 14 & $-6 \pm 0$ & $-4+4$ & 550. & $-2+4$ & $+3+8$ \\
\hline & 15 & $-1 C \pm 0$ & $-6+2$ & 850 & $-3+3$ & $+2+6$ \\
\hline & 16 & $-8-2$ & $-6+2$ & 600 & $-2+3$ & $\pm 0+6$ \\
\hline
\end{tabular}

In the columns headed lateral the pressures are those taken with the patient lying on the side of the functioning lung.

Figures are not available to demonstrate the pressures in the erect posture, but, in the few cases in which this has been investigated, it has been found that the pressures approximate to those found in the dorsal position.

A consideration of the pressures in the above cases will show that theie is a constant rise in the pressures when the patient is moved from the lateral to the dorsal position. The importance of this observation will be recognized when any attempt is made to re-establish a previous pressure. This obviously can only be done with certainty when the patient occupies the same position on both occasions. Emphasis must therefore be laid on the fact that any statement of intrapleural pressures must be accompanied by a statement of the position of the patient.

Further, while the amount of the rise varies not only in different cases, but in the same case, it will be noted that the pressures are frequently doubled. As refills are nsually conducted in the position in which the pressures are lowest, 